\title{
Classic Medulloblastoma
}

National Cancer Institute

\section{Source}

National Cancer Institute. Classic Medulloblastoma. NCI Thesaurus. Code C54039.

A medulloblastoma composed of malignant cells with hyperchromatic nucleus and scanty cytoplasm. Homer Wright rosettes may be present. 